\title{
Realismo e pragmatismo em psiquiatria: um debate
}

\author{
Rafaela Zorzanelli*1 \\ Paulo Dalgalarrondo*2 \\ Cláudio E.M. Banzato*3
}

\begin{abstract}
$O$ artigo apresenta um debate sobre a natureza do objeto da psiquiatria. Apresentam-se duas perspectivas de abordagem da questão - o realismo e o pragmatismo. Segundo o realismo, as condições denominadas transtornos mentais existiriam de forma autônoma, a despeito da conceitualização humana. Já as perspectivas pragmáticas pressuporiam que transtornos mentais não são suficientemente explicados como tipos naturais, porque normas e interesses humanos sempre estariam presentes em classificações psiquiátricas. São descritas as características, diferenças e pontos de limitação dessas abordagens.
\end{abstract}

Palavras-chave: Psiquiatria, realismo, pragmatismo, classificações

\footnotetext{
${ }^{* 1}$ Universidade do Estado do Rio de Janeiro - UERJ (Rio de Janeiro, RJ, Br). *2, 3 Universidade Estadual de Campinas - Unicamp (Campinas, SP, Br).
} 


\section{RZ: Introdução}

Em recente artigo publicado no periódico oficial da Associação Mundial de Psiquiatria, o World Psychiatry, o psiquiatra americano Kenneth Kendler (2016), retoma uma questão por ele considerada fundacional no campo psiquiátrico: a natureza de seu objeto de estudo e daquilo que a psiquiatria toma como alvo de seu tratamento. Essa questão, cujo alcance não permite chegar à pretensão de uma resposta, nos autoriza a possibilidades menos ambiciosas, mas não menos interessantes. Optamos por apresentar duas das perspectivas possíveis de abordagem da dita questão fundacional que recorta tantos dos dilemas e pontos-cegos com os quais a psiquiatria em seus eixos clínicos e epistemológicos se confronta. Esta apresentação se fará por meio de um debate com dois psiquiatras e psicopatólogos brasileiros - Paulo Dalgalarrondo e Cláudio Banzato, que percorrerão o tema acima indicado, bem como seus dobramentos éticos e clínicos. Cada um deles apresentará uma perspectiva diferente. Paulo Dalgalarrondo, a perspectiva realista; Cláudio Banzato, a pragmática. Mais do que uma descrição de abordagens, encontraremos aqui um relato vivo, uma tomada de posição a partir de ângulos diferentes, em que serão expostos os pontos de vista sobre limites e alcances das perspectivas abraçadas por cada um, com seus pontos de afastamento e de conciliação. Estando a compreensão das bases conceituais dos transtornos mentais permanentemente em disputa, é importante lembrar o que salientou o psiquiatria German Berrios: “(...) os psiquiatras dificilmente podem se dar ao luxo de funcionar em estado de inocência filosófica” (2015, p. 142). Reconhecemos nas respostas dos entrevistados, um apropriado instrumento para a ampliação do debate conceitual na psiquiatria.

$\mathrm{RZ}$ - O que está em jogo no debate sobre "a realidade" dos transtornos mentais?

PD - Ao se abordar a noção de "realidade dos transtornos mentais", devem-se apontar algumas das noções básicas da posição 
realista. Esta posição se inicia com uma disposição geral em refrear nossa subjetividade, nossas preferências e tentar ver e ouvir as coisas falarem por si, isso em termos de uma disposição bem geral, ainda não desenvolvida filosoficamente. Há, aqui, uma crença básica, certa fé metafísica, de que as coisas que vemos, e que (segundo tal posição) estão no mundo, constituem uma realidade independente de nós.

Enfim, os objetos de nosso conhecimento não dependem de nossa mente para sua existência, e não somente em sua existência, mas também em seu caráter, nas propriedades de tais coisas que eventualmente conseguimos identificar de forma consistente. Esta, só para lembrar, é a posição geral do realismo, que é também uma posição intuitiva das pessoas, sobretudo para os objetos físicos e observáveis.

Nos debates em torno do realismo filosófico e do científico dá-se um passo no sentido de que, não apenas o que observamos no mundo, mas as concepções sobre o mundo partem da noção de que há um mundo real independente de nossas mentes, e que tais concepções serão tanto mais verdadeiras quanto melhor, mais fidedignamente, representarem esse mundo, quanto mais corretamente tal representação descreve, explica e prevê o que acontece no mundo. Para nossas questões, na medicina e na psiquiatria, também se deve atentar sobre aquilo que é observável e material (cianose, edema, comportamentos) ou experiências subjetivas (dor, angústia, alucinação).

Defendo aqui uma posição realista forte em relação ao mundo (realismo ontológico), e uma posição de realismo crítico em relação ao conhecimento que temos do mundo (realismo epistemológico), às teorias que formulamos (que incluem causas) e às classes que agrupamos (esta decomposição dos realismos que adoto é, em parte, a sugerida por Ian Hacking em Representing and intervening, 1983).

A existência dos comportamentos e experiências subjetivas das pessoas que identificamos como tendo alguns transtornos mentais (de certos transtornos, não de todos) independe de nossas mentes os observarem. Os recortes de tais comportamentos e experiências que configuram os chamados transtornos mentais podem ser corretos ou incorretos, a depender de identificar agrupamentos consistentes, agrupamentos que existem no mundo independentemente de nós os identificarmos. Assim, em uma hipotética ilha com um povo e uma cultura que nunca teve contato com a medicina e psiquiatria ocidental, poderia haver, nesta visão, pessoas com demência, delirium, esquizofrenia, transtorno bipolar ou autismo (caso os recortes que fazemos e que constituem tais transtornos for, de fato, consistente, identificar algo objetivo, que nos casos citados me parece em certo grau, ser o caso). 
Em resumo, defendo uma posição de realismo ontológico em relação a comportamentos e estados mentais. Avanço em tal realismo em relação à possibilidade de existência de classes, no caso, a existência real de transtornos mentais (agrupamentos de elementos mentais e comportamentais), adotando o realismo para classes (rejeitando então posições construcionistas, do tipo, "transtornos mentais são construções culturais e históricas, que não existem independentemente no mundo, mas apenas na mente daqueles que os formulam"). Penso, entretanto, que devemos adotar cautelosamente uma posição epistemológica crítica, ou seja, devemos preferir uma posição cética quanto à possibilidade de se conhecer exata e completamente as classes (no caso, os transtornos mentais) que são reais. Devemos assumir os transtornos mentais com um freio cético, que nos lembre sempre que nunca se terá acesso exaustivo nem completo à realidade, e que conhecer a realidade das classes (e também das teorias e causas) será sempre uma questão de grau, de conhecer mais ou menos, melhor ou pior, tal realidade (tais classes, tais transtornos), mas nunca a sua totalidade (sigo aqui de perto, Karl Jaspers, para quem as totalidades não são passíveis de conhecimento completo e exaustivo). Nunca poderemos conhecer a esquizofrenia, o autismo, na sua totalidade e com absoluta perfeição; nossas teorias, descrições, noções de causa, são e serão sempre, aproximações da realidade.

CB - Talvez valha a pena iniciar a resposta com algumas palavras sobre o termo "realidade". Parafraseando Ian Hacking, podemos dizer que "realidade" é um conceito e tanto. Não pretendemos discuti-lo aqui, mas apenas indicar certos aspectos operativos no debate sobre os transtornos mentais. O primeiro deles, de natureza ontológica, seria que realidade implica algo que tem existência independente dos constructos e interesses humanos, que não é mero produto ou projeção da mente humana. O segundo, de natureza epistemológica, diz respeito ao constrangimento que essa realidade independente impõe a nossos conceitos, impedindo que nossos esquemas conceituais girem no vazio. Não se trata somente da capacidade dos conceitos apreenderem o que existe, mas da resistência exercida por uma realidade que os ultrapassa e que não se deixa plasmar de qualquer maneira. Entretanto, nesse debate em que se indaga se os transtornos mentais existem de fato (isto é, se sua existência independe dos constructos e interesses humanos), e se os nossos conceitos capturam aspectos relevantes dessa realidade independente e que neles se ancoram, o que está em jogo fundamentalmente, creio, é a questão da legitimidade do objeto da psiquiatria. Legitimidade como objeto científico e como base de prática social, sendo prevalente a ideia de que a 
segunda deveria decorrer da primeira. No fundo, penso, há uma busca pela garantia de que não são apenas as nossas preferências e valores de diversos tipos que dão forma aos nossos conceitos sobre os quais a teoria e a prática psiquiátrica se apoiam. Em outros termos, na visão dominante, parece que a condição essencial para sustentar a legitimidade científica e social dos transtornos mentais seria antes exorcizar o fantasma de um normativismo forte.

$\mathrm{RZ}$ - Sustentar a ideia de que o sofrimento mental é real em sua multiplicidade de apresentações significa o mesmo que defender que transtornos mentais são reais? É possivel equacionar o sofrimento mental aos conceitos de que dispomos para abordá-los?

PD - Considero o sofrimento mental real em sua multiplicidade de apresentações, uma realidade existencial, mas isto não implica que os transtornos mentais recortados agora e que se pensa relacionados a tal sofrimento sejam necessariamente reais. O corte pode ter sido feito de forma equivocada. Volto para a questão anterior, um ponto é defender que possa haver transtornos mentais reais, outra coisa é afirmar que tal ou qual transtorno recortado pela psiquiatria contemporânea é consistente, reflete mais aproximadamente possível a realidade, outra ainda é relacionar tal sofrimento mental com tal ou qual transtorno. Pode-se supor que o sofrimento de uma pessoa com demência, esquizofrenia ou autismo é real, tal sofrimento pode ou não estar relacionado a tal ou qual condição e o recorte que constitui tal condição pode ser ou não ser o mais próximo possível da realidade, ou seja, pode ser mais ou menos verdadeiro (a posição realista se articula com muita frequência a uma concepção de verdade aristotélica, ou seja, verdade como correspondência).

O sofrimento humano, mental e físico, é algo mais amplo que os supostos transtornos mentais. Ele está presente como experiência importante na maior parte das pessoas com transtornos mentais, mas também está presente na experiência humana de forma geral, independente dos transtornos. Assim, ele não legitima a existência real dos transtornos. Também não creio que se possa equacionar ou dar conta do sofrimento mental sempre o aproximando de transtornos mentais; esta seria uma visão empobrecida da realidade humana. A dor das perdas, o confronto com a morte própria e de pessoas próximas, as angústias das incertezas e das certezas, os sofrimentos relacionados às guerras, tortura, genocídio, miséria, tudo isso independe de transtornos mentais. Pessoas com demência avançada, autismo ou mania podem não ter a experiência do sofrimento, embora tenham transtornos mentais muito graves. Há assim tanto relações como certa autonomia entre essas duas 
dimensões da experiência humana, a do sofrimento mental e a dos transtornos mentais.

CB - Um pequeno preâmbulo: quando um adjetivo como "real" é utilizado, é importante perceber em oposição a que ele está sendo empregado. Claro que as apresentações e expressões do sofrimento mental são múltiplas e diversas. Mas o que seria um sofrimento mental "não real"? Qual é o termo contrário implícito aqui? Ilusório, falso, fingido, encenado? De resto, quem poderia, de boa fé, questionar a realidade incontornável do sofrimento mental humano? Sobre as duas perguntas, minhas respostas são curtas: não e não. É preciso evitar a todo custo a conflação de problemas. Da realidade do sofrimento mental, não se depreende, de forma direta alguma, a realidade dos transtornos mentais. Podemos dizer que nossos conceitos relativos aos transtornos mentais representam tentativas (dentro de um registro específico) de conferir sentido, de explicar e de permitir intervenções sobre certos tipos de sofrimento (e de comportamentos não associados a sofrimento, vale acrescentar) que, por razões variadas, frustram nosso entendimento (causando perplexidade) e/ou nossas expectativas (na medida em que interferem com o curso de uma existência). Evidentemente, qualquer sofrimento mental pode ser descrito em matrizes diversas. Não há exclusividade, tampouco primazia $a$ priori de qualquer registro descritivo particular. As diferentes matrizes descritivas, incluindo aí o próprio arcabouço conceitual da psiquiatria, competem entre si em termos do apelo que provocam, da concepção de vida que trazem embutidas, dos valores (implícitos e explícitos) que priorizam e das consequências implicadas pela adoção de cada uma delas (inclusive a possibilidade de se modificar efetivamente um determinado estado de coisas indesejável).

RZ - Dentro do debate filosófico sobre os "tipos", quais seriam os modelos com maior apelo e utilidade para pensarmos o caso dos transtornos mentais?

PD - Nesse debate sobre "tipos" o principal confronto atual, me parece, é entre tipos naturais e tipos práticos ou pragmáticos. O primeiro desafio é verificar se as entidades nosológicas, as síndromes ou transtornos, se constituem como "tipos", antes mesmo do debate se tais tipos são naturais ou pragmáticos. Há fenômenos mais bem contínuos e fenômenos com (na verdade, graus de) descontinuidade. O termo "tipo" ou kind frequentemente (mas não obrigatoriamente) pressupõe certo grau de descontinuidade, certa característica de formar um agrupamento relativamente autônomo e consistente de fenômenos mais básicos. Pois bem, esse me parece já um ponto bem 
difícil. Isto também se dá na medicina física; hipertensão arterial, diabetes, obesidade, assim como nível e frequência de ansiedade e insônia são fenômenos quantitativos e contínuos que a medicina e a psiquiatria recortam a partir de um ponto, tendo como norte principalmente suas consequências pragmáticas (veremos isto adiante). AIDS, glioblastoma multiforme, endocardite, assim como autismo e esquizofrenia, implicam uma descontinuidade mais pronunciada; se adequam mais à ideia de tipo.

$\mathrm{Na}$ natureza dos fenômenos biológicos e mentais há basicamente variabilidade nas estruturas e funções corporais e mentais; considerar certo padrão de variabilidade como patológico (como doença, como um transtorno) ou sadio é uma decisão inteiramente pragmática, que responde a valores. Valores, no meu modo de ver, são elementos pragmáticos da mente e atividade humana. Assim, a constituição de um recorte assumido como transtorno mental com muita frequência responde a uma demanda pragmática. Os transtornos mentais, se forem tipos consistentes, serão então tipos naturais com uma dimensão, com repercussões e consequências pragmáticas.

Os transtornos mentais não formam um conjunto homogêneo da natureza, os diferentes transtornos foram e são constituídos por recortes que obedecem a diferentes lógicas e necessidades. Assim, enfatizo que parte dos transtornos mentais com os quais trabalhamos são mais bem concebidos como tipos naturais exclusivamente; outra parte, seria de tipos pragmáticos exclusivamente, e ainda outra parte seria uma mescla de tipos naturais e tipos pragmáticos, ao mesmo tempo.

CB - É inegável o forte apelo exercido por uma concepção ontológica de doença, isto é, a visão de doença como uma entidade autônoma e delimitada, com agentes etiológicos bem definidos, fisiopatologia conhecida e inscrição corporal característica. Algumas doenças infecciosas exemplificam com propriedade esse ideal operativo. Embora o cenário da medicina atual seja infinitamente mais complexo do que isso, com admissão da enorme heterogeneidade de condições que constituem seu objeto, assim como da vasta gama de formas de entendimento mobilizadas para apreender tais condições, existe uma tendência, penso, de se acoplar, muitas vezes de maneira inadvertida, uma posição realista sobre as doenças com a ideia de que estas sejam tipos naturais (descontinuidades delimitadas presentes na natureza, cuja existência independente por completo dos conceitos humanos). Por certo que a potência explicativa e preditiva das ciências naturais e a história de sucesso da medicina científica com o progressivo desvelamento dos mecanismos etiológicos e fisiopatológicos subjacentes às doenças e consequente desenvolvimento de 
novas formas eficazes de intervenção, contribuem sobremaneira para o apelo desse modelo que poderíamos chamar de realista. Acontece que a adoção de um modelo realista não é a única opção que se coaduna bem com a ciência. Um modelo alternativo é o pragmático, que também é francamente próciência e que de forma alguma pode ser considerado antirrealista. Nos marcos do modelo pragmático, ao lado de uma deflação ontológica (nossos constructos não precisam "dissecar a natureza em suas juntas" ou espelhar os blocos autônomos constitutivos da realidade), a ênfase recai sobre as noções de propósito e utilidade: é o interesse humano que dirige o conhecimento do mundo. Assim, admite-se que a realidade possa ser recortada de diferentes maneiras dependendo dos nossos objetivos (mas não de qualquer maneira, evidentemente, pois há constrangimentos impostos pela realidade). $\mathrm{O}$ ponto é que não há um recorte que seja absoluto e verdadeiro, válido em todos os casos, em detrimento dos demais que seriam artificiais e falsos.

$\mathrm{RZ}$ - Como você vê as diferenças entre duas das principais posições desse debate, isto é, realista e pragmática?

$\mathrm{PD}$ - Os tipos psiquiátricos, as classes, as categorias nosológicas se 534 assemelhariam mais a classes naturais, como os elementos químicos (hidrogênio, ouro, carbono), cujas dobras, pontos de recorte, seriam o peso atômico, o número de prótons de seus átomos, ou as espécies animais ou botânicas, individualizadas no mundo por isolamento reprodutivo ou estrutura morfológica, genética, funcional etc., ou seja, classes que existiriam por si no mundo, independentes das mentes humanas havê-las concebido. A outra posição indica que as categorias psiquiátricas seriam mais próximas dos gêneros literários (como poesia épica ou lírica, ou prosa, subdividida em conto, novela e romance etc.) ou formas musicais (fuga, forma-sonata, concerto grosso, sinfonia etc.), estruturas criadas inteiramente pela cultura, por mentes humanas, não havendo dobras a serem identificadas, mas sim dobras criadas e recriadas intencionalmente para determinados fins. Retomo a ideia antes exposta de considerar as categorias psiquiátricas como não homogêneas, heteróclitas, podendo tais categorias ser tipos naturais e/ou pragmáticos. Por exemplo, algumas categorias, como demência, delirium, autismo, TAB e esquizofrenia, me parecem piores candidatos a constructos pragmáticos do que outras como transtorno borderline, sociopatia, transtorno pedofílico, skin-picking, transtorno de oposição desafiante, transtorno do jogo patológico, que mais claramente respondem a normas e valores culturais marcadamente contingentes das sociedades ocidentais modernas. 
$\mathrm{CB}$ - Penso que as duas posições divergem fundamentalmente em matéria de pressupostos e expectativas. Em outros termos, elas diferem sobre as suposições de fundo sobre a relação entre conhecimento humano e realidade e sobre o que funciona como ideal operativo em cada caso. Podem não existir diferenças programáticas muito nítidas. Assim como é possível que ambas as posições engendrem práticas bastante similares no campo clínico ou da investigação científica. Entretanto, tal similaridade não deve mascarar o fato de que adotar uma ou outra posição pode comportar grandes implicações. Simplificando bastante: no modelo realista, a última palavra é da natureza (entendida em sentido amplo, como realidade independente das construções humanas); no modelo pragmático, ainda que a natureza seja conhecida intimamente e por completo (isto é, mesmo supondo que não existam limites epistemológicos), não há última palavra. Como os interesses humanos são diversos (e variam historicamente), nenhum recorte da natureza é definitivo.

\section{$\mathrm{RZ}$ - Qual é a consequência (ética e clínica) de se adotar uma posição ou outra? \\ PD - As consequências éticas e clínicas me parecem muito importantes,} sendo, entretanto, quase sempre imprevisíveis. A opção realista faz uma aposta de que o conhecimento real e objetivo das categorias diagnósticas mais corretamente possível recortadas irá implicar, no fim das contas, uma eficácia maior da clínica. Se o conhecimento mais preciso e correto da biologia molecular de uma série de neoplasias e doenças infecciosas como AIDS tem proporcionado uma eficácia maior relacionada ao tratamento com implicações para a sobrevida e a qualidade de vida de pessoas com câncer ou AIDS, da mesma forma um conhecimento mais profundo e correto, por exemplo, da esquizofrenia, do autismo, do TAB, nos forneceria, em tese, a possibilidade de intervenções mais eficazes, reduzindo o sofrimento e as limitações funcionais das pessoas acometidas. Assim, as consequências éticas e clínicas da posição realista, me parece, são projetadas num ponto mais remoto, no futuro; as consequências da posição pragmática se concentram, talvez, no curto e médio prazo, se preocupando de forma talvez mais "realista", com suas implicações. Tenho a impressão que, tendo isso em conta, as classificações psiquiátricas têm se modificado: de posições que se propunham realistas (do realismo radical do cientificismo) do século XIX e primeira metade do XX, para posições mais pragmáticas, na segunda metade do XX e no período atual. Mas essa é uma impressão que precisa ser mais bem avaliada. 
CB - Diria que a posição pragmática é mais modesta (em termos ontológicos) e mais cautelosa (em termos epistemológicos). É como se ela trouxesse em seu bojo uma vacina contra a reificação e o dogmatismo. Obviamente isso não quer dizer que a posição realista é, em si, reificante ou dogmática, apenas que ela parece mais sujeita a tais tipos de abusos. Outro aspecto digno de nota é que a posição pragmática, que confere protagonismo aos propósitos e interesses humanos, convive melhor com o normativismo. Penso que o reconhecimento do papel central dos valores e a recusa cabal de reificações e dogmatismos têm ressonâncias éticas profundas na clínica, na medida em que, neste enquadre, nenhum a priori absoluto organiza o encontro clínico e noções e conceitos de diferentes campos e matizes podem ser convocados e negociados em cada caso particular.

$\mathrm{RZ}$ - Um tema implícito neste debate é o da relação entre a ordem natural dos fenômenos e as normas morais, ou como a natureza (e os recortes e pressupostos que fazemos dela) pode servir como fonte de indicações morais sobre como viver. Como você entende essa questão no cerne do debate em foco?

PD - Na posição realista há certa crença ou aposta na isenção da ciência em relação aos valores. De modo geral, a posição pragmática aceita bem melhor a ideia de que ciência e valores são, de fato, indissociáveis. Minha posição neste ponto é de que, no dia a dia, na execução das práticas científicas, e certamente com maior ênfase nas práticas médicas e clínicas, conhecimentos científicos, teóricos, descritivos, classificatórios, estão intimamente mesclados a valores. A posição realista pode conceber um mundo de fatos em contraposição a um mundo de valores. Penso que tal contraposição pode, em alguns casos, ser útil e interessante. Em tese, o mundo é como é, independente de normas, de valores, de ideais. As normas e valores são fundamentais, em muitas situações são mais relevantes para a vida diária do que os conhecimentos factuais e objetivos. Mas normas e valores não fazem automaticamente que o mundo seja desta ou daquela forma; é preciso um esforço humano esclarecido e voluntário para que as coisas se dirijam para este ou para aquele lado visado. Assim, a posição realista é compatível com tomadas de posições normativas e valorativas, no sentido de uma prática clínica humanamente respeitosa e cuidadosa, podendo responder, por exemplo, a valores claramente normativos como equidade, justiça, solidariedade e reciprocidade, valores estabelecidos pelas pessoas, independentemente dos fatos observados na natureza. Nada desses valores e normas existe na natureza, mas nós 
podemos assumi-los arbitrariamente como pistas, guias, indicativos, para uma clínica melhor, ou para um mundo melhor.

CB - Entendo que essa passagem da descrição para a prescrição é indevida (lembrar a advertência de Hume: no ought from is). Por mais que a ordem natural dos fenômenos seja conhecida e que as restrições e constrangimentos impostos pela natureza sejam levados em conta, disso não se depreendem indicações morais sobre como a vida deve ser vivida, sobre o que ser buscado numa existência ou sobre o que conta como uma vida realizada. Como salientei antes, penso que os próprios recortes da natureza atendem a interesses humanos. Defendo assim a ideia de que o normativismo, em algum grau, é inevitável na medicina (de modo geral) e na psiquiatria (em particular). E finalizo reafirmando que, em minha opinião, a posição pragmática permite articular tais elementos de um modo que faça mais justiça à complexidade e aos desafios da clínica.

\section{$\mathrm{RZ}$ - Considerações finais}

A tarefa de fazer uma coda para um debate tão prolífico fica tão mais difícil quanto mais nos detemos aos temas que poderiam ser depreendidos, inferidos, discordados, esclarecidos, desdobrados a partir das inúmeras ideias frutíferas surgidas nos conteúdos das respostas. Começaria pela tentativa de partir de um solo comum, para, assim, colocar algumas questões.

Concordamos que o debate realismo versus pragmatismo expressa duas das posições possíveis sobre formas de se conceber a natureza do objeto da psiquiatria (o que envolveria os conceitos que giram em torno do campo, tais como sintoma, síndrome, transtorno mental, dentre outros). Poderíamos dizer que o debate geral no campo filosófico, quando aplicado ao campo particular da psiquiatria, diz respeito ao quanto esses conceitos - e sobretudo, o conceito de transtorno mental - é considerado real (uma entidade passível de ser encontrada na natureza) ou não. Um ponto de pausa. No caso do pragmatismo, o quanto um transtorno mental é considerado real ou não, não é a melhor forma de colocar a questão, pois talvez essa nem sequer seja a pergunta em torno da qual girem as preocupações dessa abordagem, mas sim, se e o quanto os conceitos são úteis para operar no mundo tal como o conhecemos. Se são reais ou não, é algo que escaparia do campo de preocupações pragmáticas.

Por um lado, encontramos na perspectiva realista uma abordagem intuitiva, em que as características ou propriedades de um transtorno mental seriam independentes do que os seres humanos pensam a esse respeito, 
dos conceitos e atividades humanas (mind-independent events), possuindo atributos que lhes seriam inerentes, obedeceriam a leis científicas e condições definidas, que persistiriam através do tempo em diferentes culturas. É a natureza o elemento prioritário a dividir os limites entre aquilo que é dela e aquilo que é seu outro: os valores humanos, a arte, a cultura, o socius. A alguns fica reservada a possibilidade de falar em seu nome, desvelá-la, decodificá-la por meio de uma apreciação treinada, tal como médicos, cientistas e outros. Certamente, é essa abordagem a que mais se aproxima, por conciliação epistemológica, das perspectivas biomédicas — os cientistas descobrem o que as coisas já são previamente, na natureza. Assume-se uma visão da natureza (supostamente acessível à objetividade científica) como entidade contraposta ou suficientemente diferenciada da cultura e da subjetividade (cujo acesso por métodos objetivos seriam mais controversos e/ou desvantajosos). Supõe-se ainda que a descoberta da natureza inerente às coisas pode nos levar a um sistema de classificação (e por consequência, de diagnóstico e de tratamento) mais eficaz. O ideal buscado é, portanto, de uma classificação mais próxima possível da natureza, ou mesmo, de seu espelho.

Por outro lado, as perspectivas pragmáticas caminham em direção con538 traintuitiva, admitindo a insuficiência da ideia de propriedades específicas dos tipos naturais como critério para classificação de transtornos mentais. Critérios classificatórios seriam sempre pragmáticos, respondendo a interesses específicos, e definidos por constructos humanos. Não poderiam, desse modo, pertencer, por premissa, à esfera da natureza. Ainda que assumam esse afastamento da perspectiva realista, a abordagem pragmática não pressupõe um antirrealismo metafísico, tampouco nega que transtornos mentais tenham ou possam ter estruturas internas. Seu ponto inegociável é a recusa da pressuposição de que tais estruturas determinariam por si mesmas seu pertencimento a categorias classificatórias (Zachar, 2002).

De acordo com essa perspectiva, o efeito de nomeação da classificação não é um desvelamento da natureza de um transtorno mental, mas uma prática situada, sobre a qual é importante reconhecer os determinantes sociais e culturais. Se o reconhecimento dos valores nas práticas classificatórias se torna importante, isso não significaria um menosprezo às bases biológicas ou a chamada "realidade" dos transtornos mentais. Se, na abordagem realista, a natureza é um grande eixo de apoio, do ponto de vista pragmático, a natureza pode ser de interesse em suas regularidades, mas a classificação dessas regularidades em tipos seria uma ação humana, e não uma propriedade da natureza falando por si mesma. 
A comparação das duas abordagens não pretendeu resolver o problema do que conta ou não como cientificamente legítimo nem do que é psicopatologicamente mais válido ou mais confiável, mas apresentar perspectivas divergentes de compreensão das classificações psicopatológicas. Zachar e Kendler (2012) fazem uma interessante comparação da remoção de Plutão, da classe dos planetas, e da homossexualidade da categoria de doença, na segunda edição do DSM. Essas duas controvérsias tão diferentes têm o ponto em comum de serem casos de "descategorização", em que o conhecimento que se tinha sobre o assunto até então foi amplamente colocado em questão. $\mathrm{O}$ alvo dos autores é ressaltar que para Plutão não importa ter sido destronado de seu posto de planeta do sistema solar, mas para alguém que se sente atraído(a) sexualmente e afetivamente por outra pessoa do mesmo sexo/gênero tem grande consequência ser classificado como um "portador de um transtorno psiquiátrico" ou não. Talvez esse seja um exemplo ilustrativo de que, menos do que a disputa entre classificações melhores que as outras, é necessário levar em conta os usos que produzem em um mundo de valores, em que as intervenções psiquiátricas interferem no modo como experiências individuais e coletivas são vividas.

Seria importante dizer que, frequentemente, há menção a uma terceira perspectiva que pode se assemelhar, em alguns pontos, à pragmática, mas que com ela não se confunde, que é a construtivista, embora ela não faça parte das perspectivas aqui abordadas. Essa última assume que transtornos mentais são necessariamente constructos da cultura - o que tem levado os leitores apressados a crer que o sofrimento mental não exista, porque seria o produto de superestruturas, em geral, maléficas (porque geram doenças) como o capitalismo e afins. Sem tirar o peso da máquina capitalista na formação de nossos sofrimentos, o que certo tipo de construtivismo assevera é que a pressuposição de um conceito como um constructo não lhe retiraria o status de realidade, mas significaria dizer que coisas, objetos ou ideias - até mesmo aqueles entendidos como inteiramente pertencentes ao domínio da natureza - não existiriam sem convenções, práticas e nomeações humanas. Nesse sentido, a própria "realidade", esse conceito com o qual dialogamos a todo tempo, seria por princípio, também um resultado de práticas e não um objeto inerte, como um pedaço de terra inexplorado pelo homem, pronto para ser descoberto.

Dito isso, novas interrogações surgem, na expectativa de que possam se transformar em um espaço futuro para novos diálogos:

- Ao postular a ideia de que os transtornos mentais independem daqueles que os observam, não estaríamos mais próximos da pressuposição de 
essências transculturais das doenças mentais? Nesse sentido, estaríamos optando por oferecer à natureza a palavra final sobre a verdade da doença mental, em um campo em que a biologia é condição necessária para a formação de quadros clínicos, embora a norma (ou a cultura) talvez não lhes seja parte menos importante. Seria possível, diante disso, manter uma posição realista sem necessariamente ser essencialista?

- Kenneth Kendler (2016) aponta uma crítica à postura do pragmatismo em psiquiatria, que qualifica como falta de preocupação com a "busca da realidade" dos transtornos acarretando a falta de legitimação de condições de sofrimento, tanto dos pacientes quanto de seus parentes e cuidadores. Disso decorreria a necessidade das abordagens pragmáticas se comprometerem com a busca da materialidade dos transtornos mentais. A propósito, a crítica de Kendler parece se endereçar muito mais ao que, na realidade do Brasil, seria a nuance mais radicalmente construtivista das perspectivas sobre o objeto da psiquiatria e mesmo da psicologia e da psicanálise - mas ele a endereça à pragmática, dentro de seu contexto cultural. A despeito dessa diferença cultural notável do endereçamento da crítica de Kendler, que precisa de ajustes ao ser recebida em nosso meio, há um ponto importante por ele levantado, que é o possível descompromisso ou desinteresse - não exatamente de psiquiatras, mas também de outros campos profissionais engajados com a saúde mental - na materialidade dos transtornos mentais. Como se fosse inconciliável que de médicos se requisitasse algum saber sobre o sofrimento mental, bem como de psicólogos e psicanalistas não se pleiteasse mais conhecimento sobre a materialidade do corpo em sofrimento. Dito isso, até que ponto os estudos sobre a cognição/mente incorporada em psiquiatria (Thomas Fuchs, Louis Sass, Giovanni Stanghellini, Josef Parnas, Dan Zahavi, Shaun Gallagher e outros) não poderiam nos ajudar a construir essa ponte que ainda nos parece longe de estar realizada?

Esperamos que o artigo seja um ponto de partida para outros debates e que não incite qualquer tipo de "posição genérica e mais correta a ser defendida para todos os casos". Que gere perguntas sobre as diversidades de posições existentes, dúvidas sobre os posicionamentos já estabelecidos, e que abra a possibilidade de, conhecendo as propostas de cada abordagem, reconhecer, utilizar e manejar, em cada uma delas, seus pontos de eficiência e de limite na especificidade das situações com que nos deparamos em nosso cotidiano. 


\section{Referências}

Berrios, G. E. (2015). Rumo a uma nova epistemologia da psiquiatria. São Paulo: Escuta.

Hacking, I. (1983). Representing and Intervening. Introductory Topics in the Philosophy of Natural Science, Cambridge: Cambridge University Press.

Kendler, K. (2016). The nature of psychiatric disorders. World Psychiatry, 15(1), 5-12.

Zachar, P. (2002 Sept.). The practical kinds model as a pragmatist theory of classification. Philosophy, Psychiatry, \&Psychology, 9(3).

Zachar, P.; Kendler, K. (2012). The removal of Pluto from the class of planets and homosexuality from the class of psychiatric disorders: a comparison. Philosophy, Ethics, and Humanities in Medicine, 7(4).

\section{Resumos}

(Realism and pragmatism in Psychiatry: a debate)

This paper presents a debate on the nature of the object of Psychiatry. Two approaches to the issue are discussed: realism and pragmatism. According to realism, would exist autonomously the conditions known as mental disorders regardless of human conceptualization. Pragmatist perspectives assume that mental disorders are not sufficiently explained as natural types, since human norms and interests are always at stake in the making of psychiatric classifications. The specific features, differences, and limitations of both approaches are described.

Key words: Psychiatry, realism, pragmatism, psychiatric classification

(Réalisme et pragmatisme em Psychiatrie: un débat)

Les auteurs présentent une réflexion critique à propos de la nature de l'objet de la psychiatrie. D'emblée, ils postulent deux voies [approches] majeures permettant d'explorer cette question fondamentale: le réalisme et le pragmatisme. Selon le réalisme, les troubles mentaux existent comme des entites autonomes, de facon independant d'une structuration conceptuelle. D'autre part, l'approche pragmatique met en avant les enjeux sociaux ce qui permet d'en déduire et d'affirmer que les troubles mentaux ne sont pas réductible à de types naturels. Enfin, les auteurs examinent brièvement et mettent en évidence les caractéristiques et limites de ces différentes approches dans la clinique psychiatrique.

Mots clés: Psychiatrie, réalism, pragmatisme, classsifications psychiatriques 
(Realismo y pragmatismo en Psiquiatría: un debate)

El artículo presenta un debate sobre la naturaleza del objeto de la psiquiatría. Son discutidas dos perspectivas del problema: realismo y pragmatismo. Para el realismo, los trastornos mentales existen autónomamente, a pesar de la conceptualización humana. Las perspectivas pragmáticas suponen que los trastornos mentales no pueden ser explicados suficientemente como tipos naturales, pues las clasificaciones psiquiátricas son siempre atravesadas por normas e intereses humanos. Son descritas las características, diferencias y límites de ambos enfoques.

Palabras clave: Psiquiatría, realismo, pragmatismo, clasificaciones psiquiátricas

(Realismus und Pragmatismus in der Psychiatrie: eine Debatte)

In diesem Artikel präsentieren wir eine Debatte über die Natur des Objektes in der Psychiatrie. Wir bieten somit zwei perspektiven bezüglich dieser Problematik- den Realismus einerseits, und den Pragmatismus als gegen Stellung. Für den Realismus würden die sogenannten Bedingungen der Psychiatrischen Störungen auf autonomer Weise vorhanden sein, und dies trotz menschlicher Konstruktionen. Pragmatische Perspektiven setzten voraus das Psychische Störungen nicht genügend durch 'natural kinds' erklärt werden können, weil menschliche Normen und sonstige Interessen sonst immer in Psychiatrischen Klassifikationen zu finden sind. Die Charakteristiken, Unterschiede und Einschränkungen werden dieser Perspektiven werden hier beschrieben.

Schlüsselwörter: Psychiatrie, Realismus, Pragmatismus, Psychiatrische Klassifikationen

（精神分析学中现实主义典范与实用主义典范之讨论）

本文主旨是讨论精神病的本质究竟是为何物。他们提出两种可以供研究 的典范: 现实主义和实用主义。从现实主义的典范来说, 精神病即是一种内源 性, 自发性疾病, 不管人们对其进行什么样的概念化的总结。而实用主义典范 认为由于人类的利益与各项标准始终参杂于精神病的诊断和分类过程之中, 因 此, 他们觉得精神问题具有后天性, 不全部属于内源性疾病。本文作者就此两 种典范的特征、差异以及局限性做出了详细阐释。

关键词: 精神病学, 现实主义, 实用主义, 精神病分类

Citação/Citation: Zorzanelli, R.; Dalgalarrondo, P.; Banzato, C. E. M. (2016, setembro). Realismo e pragmatismo em psiquiatria: um debate. Revista Latinoamericana de Psicopatologia Fundamental, 19(3), 527-543.

Editores do artigo/Editors: Prof. Dr. Claudio e M. Banzato e Profa. Dra. Rafaela Zorzanelli 
Recebido/Received: 20.5.2016/ 5.20.2016 Aceito/Accepted: 28.7.2016 / 7.28.2016

Copyright: (C) 2009 Associação Universitária de Pesquisa em Psicopatologia Fundamental/ University Association for Research in Fundamental Psychopathology. Este é um artigo de livre acesso, que permite uso irrestrito, distribuição e reprodução em qualquer meio, desde que o autor e a fonte sejam citados / This is an open-access article, which permits unrestricted use, distribution, and reproduction in any medium, provided the original authors and sources are credited.

Financiamento/Funding: Os autores declaram não terem sido financiados ou apoiados / The authors have no support or funding to report.

Conflito de interesses/Conflict of interest: Os autores declaram que não há conflito de interesses / The authors have no conflict of interest to declare.

\section{RAFAela ZorZANelli}

Psicóloga; Doutora em Saúde Coletiva; Professora Adjunta do Instituto de Medicina Social da Universidade do Estado do Rio de Janeiro - UERJ (Rio de Janeiro, RJ, Br).

Rua São Francisco Xavier, 524 - Pavilhão João Lyra Filho, $7^{\circ}$ andar/blocos D e E, e $6^{\circ}$ andar / bloco E - Maracanã

20550-013 Rio de Janeiro, RJ, Br

Fones: (21) 2334-0235 / 2334-0354

rtzorzanelli@gmail.com

\section{Paulo Dalgalarrondo}

Psiquiatra; Doutor em Psiquiatria; Doutor em Antropologia; Professor Titular do Departamento de Psicologia Médica e Psiquiatria da Faculdade de Ciências Médicas da Universidade de Campinas - Unicamp (Campinas, SP, Br).

Rua Tessália Vieira de Camargo, 126 - Cidade Universitária “Zeferino Vaz"

13083-887 Campinas, SP, Br

Fone: (19) 3521-7206

pdalga@fcm.unicamp.br

\section{Cláudio E. M. Banzato}

Psiquiatra; Doutor em Filosofia; Professor Titular do Departamento de Psicologia Médica e Psiquiatria da Faculdade de Ciências Médicas da Universidade de Campinas - Unicamp (Campinas, SP, Br).

Rua Tessália Vieira de Camargo, 126 - Cidade Universitária “Zeferino Vaz"

13083-887 Campinas, SP, Br

Fone: (19) 3521-7206

cbanzato@fcm.unicamp.br

This is an open-access article, which permits unrestricted use, distribution,

(cc) BY-NC and reproduction in any medium for non-commercial purposes provided the original authors and sources are credited. 